\title{
CONTRIBUIÇÕES DO PROGRAMA INSTITUCIONAL DE BOLSAS DE INICIAÇÃO À DOCÊNCIA (PIBID) PARA A FORMAÇÃO DOCENTE NA EDUCAÇÃO PROFISSIONAL
}

\author{
Ana Sara Castaman; Camila Gomes Nogueira \\ Instituto Federal de Educação, Ciência e Tecnologia do Rio Grande do Sul - Campus Sertão \\ DOI: 10.15628/rbept.2018.6052
}

Artigo submetido em jun/2018 e aceito em ago/2018

\begin{abstract}
RESUMO
A formação docente na educação básica e profissional encontra-se em constante debate, nos últimos anos. As atuais políticas para formação docente evidenciam a necessidade de se refletir sobre a práxis dos futuros docentes e também daqueles que atuam em sala de aula. Sendo assim, objetivando contribuir para o enriquecimento das pesquisas acerca da formação docente para a educação profissional, este estudo é um recorte desta pesquisa e visa investigar quais são as contribuições do Programa Institucional de Bolsas de Iniciação à Docência (PIBID) para a formação docente dos alunos bolsistas do Curso de Formação Pedagógica para docentes da educação básica e profissional do Instituto Federal de Educação, Ciência e Tecnologia do Rio Grande do Sul - Campus Sertão a partir da análise dos subprojetos desenvolvidos no curso. A partir da análise dos projetos foi possível verificar uma articulação entre as formações dos bolsistas com as atividades realizadas, contudo cabe salientar que a análise é feita a partir dos documentos o que tenciona verificar se estas atividades propostas se efetivaram no desenvolvimento dos subprojetos.
\end{abstract}

Palavras-Chave: Educação Profissional. Formação Docente. PIBID.

\section{CONTRIBUTIONS OF THE PROGRAMA INSTITUCIONAL DE BOLSAS DE INICIAÇÃO À DOCÊNCIA (PIBID) FOR THE PROFESSIONAL EDUCATION}

\begin{abstract}
Teacher training in basic and professional education has been in constant debate in recent years, and current policies for teacher training emphasize the need to reflect on the practice of future teachers as well as of those already teaching. Therefore, aiming to contribute to the enrichment of research on teacher training for professional education, this study aims to investigate what the contributions of the Programa Institucional de Bolsas de Iniciação à Docência (PIBID) for the training of scholarship students of the Teaching Training Course for teachers of basic and professional education at the Federal Institute of Education, Science and Technology of Rio Grande do Sul - Campus Sertão analyzing the development of subprojects.
\end{abstract}

Keywords: Professional Education. Teacher Training. PIBID. 


\section{INTRODUÇÃO}

A educação profissional e tecnológica (EPT) como modalidade de ensino da educação brasileira encontra desafios na formação de seus docentes, especialmente, porque ainda há um grande número de profissionais de diversas áreas munido de conhecimentos técnicos atuando no ensino, contudo, sem formação pedagógica para mediar conhecimentos teórico-prático em sala de aula.

Diante deste contexto, por vezes preocupante, evidencia-se a importância da formação docente para/na educação profissional e a implementação de políticas públicas voltadas para a esta área, de modo que se preparem os estudantes das respectivas licenciaturas para o processo de ensino e aprendizagem e os subsidie a continuidade de sua formação e/ou atuação profissional.

Frente a essas demandas, o governo federal, por meio do Decreto no 6.755, de 29 de janeiro de 2009 instituiu a Política Nacional de Formação de Professores sob o gerenciamento da Coordenação de Aperfeiçoamento de Pessoal de Nível Superior (CAPES), a qual se apresenta como fruto da colaboração entre o Ministério da Educação (MEC) e as secretarias de educação municipais e estaduais, além das intuições públicas de nível superior, na qual os cursos seriam ministrados de forma gratuita, buscando garantir a formação em nível superior para os professores em exercício nas escolas, entre os programas viabilizados por esta política estão Programa de Iniciação à Docência - PIBID.

O Programa Institucional de Bolsas de Iniciação à Docência (PIBID) vinculado ao curso de Formação Pedagógica para a Educação Básica e Profissional ofertado pelo Instituto Federal de Educação, Ciência e Tecnologia do Rio Grande do Sul (IFRS) - Campus Sertão é recente, do ano de 2011, o que sugere a análise sobre as contribuições ao mesmo.

Frente aos aspectos que permeiam a formação docente e suas políticas, o presente estudo tem como objeto de estudo o Programa Institucional de Bolsas de Iniciação à Docência (PIBID) inserido ao curso de Formação Pedagógica para a Educação Básica e Profissional, do IFRS Campus Sertão. Desta forma, este trabalho visa a conhecer como o Programa Institucional de Bolsas de Iniciação à Docência (PIBID) contribui com a licenciatura para a Educação profissional, a partir da análise documental dos dois subprojetos contemplados nos anos de 2011 e 2013, respectivamente, pelo programa no Curso de Formação Pedagógica para docentes da Educação Básica e Profissional, do IFRS - Campus Sertão.

\section{METODOLOGIA}

A metodologia empregada para realizar esta pesquisa remeteu a um estudo de caso, de cunho qualitativo, com base em pesquisa bibliográfica e documental. Os documentos analisados referem-se à legislação do PIBID e 
aos subprojetos, de 2011 e 2013, desenvolvidos por estudantes do curso de Formação Pedagógica de Docentes para Educação Básica e Profissional, do IFRS - Campus-Sertão.

Para Lüdke e André (1986) na pesquisa documental é possível identificar informações nos documentos partindo de questões e hipóteses. Para isso, contatou-se com o atual e o antigo coordenador do PIBID, do IFRS para conhecer os projetos contemplados pelo programa. Verificou-se a existência de dois subprojetos do curso de Formação Pedagógica de Docentes para Educação Básica e Profissional, do campus Sertão e, em cada um deles, analisou-se as atividades propostas e como estas convergem para a formação docente dos bolsistas do PIBID.

\section{O PROGRAMA DE INICIAÇÃO À DOCÊNCIA - PIBID}

O PIBID foi instituído a partir da Portaria Normativa $\mathrm{n}^{\circ} 38$, de 12 de dezembro de 2007. O programa é oriundo de uma ação conjunta do Ministério da Educação (MEC), por intermédio da Secretaria de Educação Superior (SeSu), da Fundação Coordenação de Aperfeiçoamento de Pessoal de Nível Superior (CAPES) e do Fundo Nacional de Desenvolvimento da Educação (FNDE), visando o fomento à iniciação à docência de estudantes em nível superior, em cursos de licenciatura presencial plena, para atuar na educação básica pública (BRASIL, 2007). O primeiro edital priorizou atender as áreas de física, química, biologia e matemática do ensino médio. A partir dos resultados positivos do PIBID e da demanda de formação de professores, em 2009 o programa foi expandido, passando a atender toda a educação básica, educação de jovens e adultos, indígenas e quilombolas.

Em 2010, o PIBID passa a ser regulamentado pelo Decreto ํㅜ 7.219, de 24 de junho de 2010, demonstrando a importância de institucionalizar e consolidar o programa. A relevância do programa para a formação inicial se evidencia ao se analisar seu propósito. De acordo com a Portaria oㅡ 260, de 30 de dezembro de 2010, são objetivos do programa:

I - incentivar a formação de docentes em nível superior para a educação básica;

II - contribuir para a valorização do magistério;

III - elevar a qualidade da formação inicial de professores nos cursos de licenciatura, promovendo a integração entre educação superior e educação básica;

IV - inserir os licenciados no cotidiano de escolas da rede pública de educação, proporcionando-Ihes oportunidades de criação e participação em experiências metodológicas, tecnológicas e práticas docentes de caráter inovador e interdisciplinar que busquem a superação de problemas identificados no processo de ensino-aprendizagem;

V - incentivar escolas públicas de educação básica, mobilizando seus professores como conformadores dos 
futuros docentes e tornando-as protagonistas nos processos de formação inicial para o magistério; e

VI - contribuir para a articulação entre teoria e prática necessárias à formação dos docentes, elevando a qualidade das ações acadêmicas nos cursos de licenciatura. (BRASIL, 2010, p.03)

Conforme se verifica no referido decreto, os projetos devem promover a inserção dos estudantes no contexto das escolas públicas, desde o início da sua formação acadêmica, para que desenvolvam atividades didáticopedagógicas, sob orientação de um docente da licenciatura e de um professor da escola. Por meio dessa interação com a escola e com professores visa à aproximação do aluno com o cotidiano escolar.

\subsection{Formação Pedagógica de Docentes para a Educação Básica e Profissional do IFRS - Campus Sertão}

As mudanças ocorridas na educação profissional supracitadas nesta escrita demonstram a pertinência de se promover a constituição profissional dos docentes de forma consistente, fazendo com que os programas de formação docente sejam um caminho para alcançar o desenvolvimento profissional do professor. Os institutos federais, conforme sua Lei de criação tem como uma de suas atribuições, a oferta de formação inicial e continuada. Nesse contexto, o programa aqui pesquisado encontra-se no Instituto Federal de Educação, Ciência e Tecnologia do Rio Grande do Sul, do Campus Sertão.

Como enfatizam Castaman, Oliveira e Rigo (2014), o período de expansão da rede federal e a abertura de concursos públicos para professores de diversas áreas evidenciaram a importância da formação pedagógica para os docentes. Com esta preocupação o Instituto Federal, Campus Sertão cria, em 2010, em regime integral, o programa especial de Formação Pedagógica de Docentes para a Educação Básica e Profissional.

O curso, segundo informações que constam em seu terceiro Projeto Político Pedagógico (2014) em vigor, tem como objetivo formar diferentes profissionais com curso superior para a docência na educação profissional de nível fundamental e médio de forma que o aluno possa obter uma compreensão crítica da sociedade e do pensamento pedagógico e suas implicações, além da mediação no trabalho educativo. Verifica-se em dados apresentados no referido PPC (2014), uma preocupação em desenvolver nos discentes, habilidades pedagógicas aliadas com a compreensão do processo educativo, como se explicita em seus objetivos específicos:

a) Formar profissionais da educação com visão global, crítica e humanística, demonstrando habilidades para a docência do processo educativo, tomando decisões e participando 
ativamente nas discussões acerca da definição de políticas educacionais;

b) Desenvolver habilidades para a docência, buscando a compreensão dos problemas educacionais e assumindo postura investigativa;

c) Proporcionar condições que permitam compreender e intervir no processo educativo por meio da organização de situações de aprendizagem considerando as especificidades e necessidades da educação básica e profissional;

d) Instrumentalizar para o planejamento da ação educativa através do domínio de conteúdos/linguagens e metodologias das áreas, visando à formação humana nas diferentes temporalidades do desenvolvimento humano (PPC, 2014, p. 16).

A preocupação com uma formação consistente deve proporcionar que o egresso seja capaz de articular conhecimento acadêmico com o contexto histórico, político, econômico, social e cultural da realidade em que está inserido, com espírito investigativo, criativo e ousado, abstraindo e resolvendo problemas, trabalhando coletiva e interdisciplinarmente (PPC, 2014). Dessa forma, ao finalizar o curso se almeja que o egresso obtenha as seguintes habilidades saberes, capacidades:

a) Promover transformações necessárias a partir de uma visão global, crítica e humanística no ambiente educacional, as quais possam refletir no contexto social;

b) Dominar conteúdos e habilidades técnicas pedagógicas e ser capazes de agir de forma lógica com método e em busca de resultados viáveis e justos;

c) Demonstrar discurso coerente que envolva a prática pedagógica, compreendendo a contradições sociais, políticas e econômicas da sociedade;

d) Trabalhar com elementos didáticos que sirvam de motivos e propiciem o interesse científico e a postura investigativa nos egressos;

e) Fazer a análise e compreender o fenômeno educativo a partir de fundamentos teóricos e metodológicos;

f) Planejar, coordenar e intervir a/na ação educativa, considerando as especificidades e necessidades da educação básica e profissional;

g) Demonstrar habilidades linguísticas (comunicação oral e escrita);

h) Trabalhar com novos recursos de comunicação;

i) Localizar, selecionar e processar as informações disponíveis; 
j) Valorizar o conhecimento científico, sua história e correlação com o cotidiano;

k) Incentivar o desenvolvimento tecnológico, comprometendo a formação ética e cidadã dos estudantes (PPC, 2014, p.1718).

Para que o perfil do egresso seja alcançado, a estrutura curricular do curso conta com uma carga horária de 956 horas, divididas em núcleos, conforme preconiza a Resolução № 2 da CNE, de 26 de junho de 1997.

Diante da análise sobre o curso, tornou-se relevante refletir a respeito da formação inicial dos docentes visto que, conforme Castaman, Oliveira e Rigo (2014), o programa de formação pedagógica para docentes se apresenta como um caminho para a necessidade de professores de culturas técnicas investirem na formação para a sala de aula.

É possível pensar na hipótese de que muitos dos estudantes do curso estejam no início de suas carreiras como docentes, o que implica na necessidade de além de articular o arcabouço teórico sobre a temática com a prática docente inicial oferecida pela experiência do estágio supervisionado e programas de incentivo a formação inicial como o PIBID.

3.2 Os subprojetos do PIBID no curso de Formação Pedagógica para Docentes do IFRS - Campus Sertão

O projeto do curso de formação pedagógica contemplado pelo PIBID é do ano de 2011, edital nº 001/2011, da CAPES. O plano de trabalho teve como título "orientação profissional para o mundo do trabalho", com a finalidade de inserção dos estudantes bolsistas do PIBID na escola, auxiliando na orientação profissional dos alunos do ensino médio. Para alcançar esse objetivo, o projeto previu o total de 20 ações, divididas em 24 meses.

O início das atividades consistiu em um diagnóstico envolvendo os bolsistas e os alunos do ensino médio a respeito das perspectivas do mundo do trabalho na região, incluindo ocupações profissionais, novas possibilidades de trabalho e interesses individuais em relação ao mundo do trabalho (IFRS, 2011). A partir do diagnóstico, o projeto previu a elaboração de ações como: workshop das profissões, programa de orientação profissional, produção de um almanaque das profissões, realização de seminários, relatos de experiências de organizações, participação com apresentação de trabalhos em eventos científicos e produção e apresentação de dossiê e livro sobre as atividades desenvolvidas no projeto.

Diante das atividades propostas no projeto em análise foi possível verificar os objetivos do PIBID, como política de formação inicial com inserção dos bolsistas no cotidiano escolar, a contribuição para a articulação entre teoria e prática com a elaboração dos materiais e sua apresentação, além do incentivo à pesquisa, com a participação em eventos e publicação de 
relatórios e livro. A relação entre teoria e prática explicita-se e vai ao encontro com a reflexão de Cunha,

\begin{abstract}
Nesse caso a prática se torna a base da reconstrução teórica, dando sentido ao estudo e aprofundamento de seus pressupostos. A teoria, também, se distancia das metanarrativas generalistas e inquestionáveis. Antes, se constitui em construtos que podem orientar a compreensão da prática, num processo intermediado por interpretações subjetivas e culturais, que ressignifiquem a teoria para contextos específicos. (CUNHA, 2011, p.100-101).
\end{abstract}

Dessa forma, a relação entre teoria e prática é reforçada no programa, contribuindo para formação inicial do estudante. Além disso, a aproximação do bolsista com o cotidiano escolar propicia uma inserção com o contexto social das escolas.

O segundo subprojeto, contemplado pelo PIBID, é do ano de 2013, edital $n^{\circ}$ 61/2013 da CAPES e entrou em vigor no ano de 2014. O subprojeto faz parte do projeto que abarcou outros seis campi do IFRS. Como objetivo institucional, o projeto antecedeu ações e/ou estratégias para inserção dos bolsistas nas escolas, com visitas para coletar informações sobre o contexto educativo, a dinâmica administrativa pedagógica e socioeconômica da mesma, condições de ensino, entre outras. Ademais, teve o objetivo de identificar em conjunto com os supervisores e outros representantes do espaço educativo, os limites e as possibilidades de ações pedagógicas de acordo com o contexto sociocultural dos educandos. As atividades inseridas no contexto escolar contemplaram a observação dos espaços e da infraestrutura; observação e acompanhamento de aulas; entrevistas com professores e estudantes; levantamento de ações desenvolvidas pelas escolas nas áreas dos subprojetos, participação em reuniões pedagógicas nas escolas e estudo dos Projetos Pedagógicos da escola (IFRS, 2013).

O planejamento das ações pedagógicas, segundo dados verificados no projeto (IFRS, 2013) são elaborados pelos bolsistas em conjunto com o coordenador da área e os supervisores. Os bolsistas deverão utilizar seus conhecimentos adquiridos das atividades de aproximação e dos estudos desenvolvidos em seus cursos com o objetivo de desenvolver propostas "[...] inovadoras e contextualizadas à realidade da escola" (p. 02). Estas ações deverão contemplar: atividade de estudo e pesquisa; compartilhamento de experiências e reflexões sobre a prática; elaboração e aquisição de materiais para desenvolvimento de aulas práticas experimentais, textos didáticos, matérias impressos, entre outros.

Em síntese cada subprojeto:

[...] primará pela produção e execução de práticas educativas que observem a diversidade regional, social, cultural e intelectual dos educandos e contribuam para a formação e a consolidação da cidadania. Além disso, busca-se uma 
diversidade de práticas em um mesmo subprojeto, com o intuito de desenvolver a linguagem, tanto de bolsistas como de educandos, em um sentido abrangente e dinâmico, pela articulação de diversas ações destinadas à organização de novas maneiras de pensar, falar, sentir e atuar para explicar e transformar o mundo (IFRS, 2013, p. 03).

O subprojeto Pedagogia, de 2013, que se refere ao Curso de formação pedagógica do IFRS-campus Sertão, foi composto por 10 (dez) bolsistas na modalidade de educação regular e educação profissional e tecnológica. As atividades previstas (na época) para o subprojeto foram desenvolvidas em três escolas da região de inserção do Campus. Como atividade de aproximação dos bolsistas com o ambiente escolar, foi realizada uma análise de conjuntura da realidade das escolas, composta pela visita dos bolsistas às instalações das escolas e elaboração de um relatório sobre as condições físicas desses ambientes. Além disso, foi organizado um dia de vivência dos bolsistas nas instituições. Foi previsto também uma escala de revezamento em duplas para a participação dos bolsistas em reuniões nas escolas, acompanhamento das discussões sobre a reformulação e Projetos Políticos Pedagógicos, se estas acontecessem nas escolas, envolvimento na preparação e execução dos conselhos de classe e reuniões com a presença da comunidade escolar (IFRS, 2013).

O projeto visou ainda a elaboração de uma listagem de referenciais teóricos contemporâneos, voltados para os saberes necessários à educação, como planejamento, acompanhamento e avaliação da aprendizagem; realização de rodas de conversas sobre as leituras destes referenciais; entrevista com os docentes das escolas participantes objetivando conhecer os referenciais teóricos adotados, a apresentação dos resultados destas análises aos professores das escolas participantes e a publicação dos resultados deste estudo (IFRS, 2013).

Em síntese, o que pode se considerar, a partir da análise dos dois projetos contemplados pelo PIBID é que as ações propostas abarcaram diversas atividades que objetivaram a aproximação de seus bolsistas com 0 contexto escolar, premissa do programa, e também, propiciaram aos bolsistas relacionar a teorização com a prática docente. Como elucida Schön (2000, p. 250), "[...] o desenvolvimento de um ensino prático reflexivo pode somar-se a novas formas de pesquisa sobre a prática e de educação para essa prática, para criar um momento ímpeto próprio, ou mesmo algo que se transmita por contágio".

Assim, ao conhecer a ação, os bolsistas têm a oportunidade de refletir sobre a mesma: desenvolver sem que precisemos dizer o que estamos fazendo. Improvisadores habilidosos ficam muitas vezes, sem palavras ou dão descrições inadequadas quando se lhes pergunta o que fazem. É claro que, sermos capazes de refletir na ação é diferente de sermos capazes de refletir 
sobre nossa reflexão na ação, de modo a produzir uma boa descrição verbal dela. E é ainda diferente de sermos capazes de refletir a descrição resultante. (SCHÖN, 2000, p. 35).

Outrossim, o desenvolvimento destas ações proporcionam aos estudantes do ensino médio e professores das escolas envolvidas, uma interação entre diferentes modalidades de ensino, nesse caso, entre a educação básica e a superior.

\section{CONCLUSÃO}

A partir da análise dos dois projetos (2011 e 2013) do PIBID, aos quais os estudantes do curso de Formação Pedagógica de Docentes para Educação Básica e participaram, foi possível verificar uma preocupação com a inserção dos estudantes no ambiente escolar, o que propicia uma aprendizagem significativa para o bolsista que inicia seu contato com seu futuro local de trabalho e também para as escolas envolvidas que tem a oportunidade de oferecer aos seus alunos atividades diversificadas e a aproximação com a universidade. Além disso, oportuniza o desenvolvimento de um professor reflexivo e especificamente na área da educação profissional possibilita no curso de formação pedagógica vivências diferenciadas para alunos já formados em áreas diversas o que oferece uma compreensão do espaço escolar e de um professor pesquisador que reflete sobre sua prática a partir do desenvolvimento da relação entre teoria e prática durante o curso.

Cabe salientar que as conclusões a que chegamos se remete a análise teórica e institucional das atividades propostas pelos subprojetos, o que implica em dizer que os projetos indicam a relevância do programa, contudo, cabe verificar se os objetivos dos subprojetos se efetivaram nas atividades realmente. Isso implica em investigar a efetivação destas atividades por meio de recursos metodológicos como entrevistas e questionários para os sujeitos participantes da pesquisa.

\section{REFERÊNCIAS}

BRASIL. Decreto $N^{\circ}$ 6.755, de 29 de janeiro de 2009. Institui a Política Nacional de Formação de Profissionais do Magistério da Educação Básica, disciplina a atuação da Coordenação de Aperfeiçoamento de Pessoal de Nível Superior -CAPES no fomento a programas de formação inicial e continuada, e dá outras providências. Disponível. em:http://www.planalto.gov.br/ccivil_03/_Ato20072010/2009/Lei/d6755.htm>. Acesso em: 10 set.2015.

Decreto no 7.219, de 24 de junho de 2010. Dispõe sobre o Programa Institucional de Bolsa de Iniciação à Docência - PIBID e dá outras 
providências. Brasília/DF $2010 . \quad$ Disponível em: <http://www.planalto.gov.br/ccivil_03/_ato2007-2010/2010/decreto/d7219.htm. $>$ Acesso em: 13 dez.2015.

INSTITUTO FEDERAL DE EDUCAÇÃO, CIÊNCIA E TECNOLOGIA DO RIO GRANDE DO SUL - IFRS. Projeto Institucional PIBID/IFRS. Vivências Docentes Compartilhadas. Edital no 01/2011/Capes. 2011.

INSTITUTO FEDERAL DE EDUCAÇÃO, CIÊNCIA E TECNOLOGIA DO RIO GRANDE DO SUL - IFRS. Projeto Institucional PIBID/IFRS. PIBID 2013. Edital oㅡ 61/2013/Capes. 2013.

CASTAMAN, A. S.; OLIVEIRA, D.; RIGO, K. A. Considerações acerca da Experiência do Programa Especial de Formação de Docentes para a Educação Profissional no IFRS - Sertão/RS. In: IV Seminário Nacional de Educação Profissional e Tecnológica (IV SENEPT), 2014, Belo Horizonte MG. Anais do IV Seminário Nacional de Educação Profissional e Tecnológica (IV

SENEPT),

2014.Disponível:<http://www.senept.cefetmg.br/galerias/Anais_2014/GT08/G T_08_x1x.PDF>Acesso em: 25 de jul.2016.

CUNHA, Maria Isabel da. Formação de Professores em tempos complexos: perspectivas conceituais e processos em tensão. JORNADAS TRANSANDINAS DE APRENDIZAGEM (13:2010: Frederico Westphalen). Ensinar e aprender num mundo complexo e intercultural: acta/ Organização (de) Edite Maria Sudbrack, Luci Mary Duso Pacheco. Frederico Westphalen: URI/FW, 2011.

LÜDKE, Menga e ANDRÉ, Marli E. D. A Pesquisa em educação: abordagens qualitativas. São Paulo: EPU, 1986.

SHÖN, Donald. Educando o profissional reflexivo: um novo design para o ensino e a aprendizagem. Porto Alegre: Artes Médicas Sul, 2000. 